\title{
Re-Evaluation of 162 Malignant Thyroid Nodules that were Interpreted as Benign Based on Ultrasound Findings
}

\section{(이 (요}

\section{Authors}

Tomoko Fujimoto ${ }^{1}$, Mitsuyoshi Hirokawa², Ayana Suzuki ${ }^{1}$, Hisashi Ota ${ }^{1}$, Maki Oshita1 ${ }^{1}$, Takumi Kudo ${ }^{3}$, Mitsuhiro Fukushima ${ }^{4}$, Kaoru Kobayashi ${ }^{4}$, Akira Miyauchi ${ }^{4}$

\section{Affiliations}

1 Kuma Hospital, Department of Clinical Laboratory, Kobe, Japan

2 Kuma Hospital, Department of Diagnostic Pathology and Cytology, Kobe, Japan

3 Kuma Hospital, Internal Medicine, Kobe, Japan

4 Kuma Hospital, Department of Surgery, Kobe, Japan

Key words

thyroid, sonography, risk of malignancy, interobserver

variation

received $\quad 16.05 .2018$

revised 19.07.2018

accepted 24.08.2018

Bibliography

DOI https://doi.org/10.1055/a-0732-5795

Ultrasound Int Open 2018; 4: E110-E116

(c) Georg Thieme Verlag KG Stuttgart · New York

ISSN 2199-7152

Correspondence

Ms. Tomoko Fujimoto

Kuma Hospital

Department of Clinical Laboratory

8-2-35

6500011 Kobe

Japan

Tel.: + 81/78/371 3721

fujimoto01@kuma-h.or.jp

\section{ABSTRACT}

Purpose The goal of this study was to estimate the risk of malignant thyroid nodules being interpreted as benign based on ultrasound findings and to clarify the pathological features of these malignant nodules.

Materials and Methods We retrospectively re-evaluated ultrasound and pathological findings for 162 malignant thyroid nodules that were initially interpreted as benign based on ultrasound findings at Kuma Hospital between April 2012 and June 2015.

Results The incidences of malignancy among "benign" thyroid nodules were $0.5 \%$ overall and $6.2 \%$ among resected nodules. In addition, $82.7 \%$ of thyroid nodules that were originally judged to have low or very low suspicion patterns were subsequently re-categorized as having high or intermediate suspicion patterns. The incidences of irregular margins (63.6\%) and low echogenicity $(36.4 \%$ ) were higher than those of punctate microcalcification (17.9\%) and the taller-than-wide shape (20.4\%). Among microcarcinomas, the incidences were 65.7\% for irregular margins and $51.4 \%$ for low echogenicity. Rim calcification with small extrusive soft tissue components and extrathyroidal extensions were not observed. After re-evaluation, $40.0 \%$ of papillary thyroid carcinomas remained benign based on their variants, such as the encapsulated, follicular, macrofollicular, and oxyphilic cell variants.

Conclusion We conclude that more careful observation, especially for lesions with irregular margins and low echogenicity, can help improve the diagnostic accuracy of thyroid ultrasonography. Furthermore, greater care may decrease the incidence of malignancy among thyroid nodules with low or very low suspicion patterns. Some variants of papillary thyroid carcinoma can have benign ultrasound findings.

\section{Introduction}

Thyroid ultrasonography (US) is widely used to detect thyroid nodules and stratify their risk of malignancy (ROM). According to the 2015 American Thyroid Association guidelines for adult patients with thyroid nodules and differentiated thyroid cancer, the sonographic patterns of thyroid nodules are divided into five patterns (high suspicion, intermediate suspicion, low suspicion, very low suspicion, and benign) that have specific ROM values [1]. The low suspicion pattern involves an isoechoic or hyperechoic solid nodule or a partially cystic nodule with eccentric solid areas but no punctate microcalcification, irregular margins, extrathyroidal extension, or taller-than-wide shape. The estimated ROM for these lesions is $5-10 \%$ [1-4] with malignancies generally involving the follicular variant (FV) of papillary thyroid carcinoma (PTC) or follicular thyroid carcinoma (FTC) [5,6]. However, no studies have performed a detailed examination of malignant nodules with benign 
US findings. The present study aimed to estimate the ROM for thyroid nodules that were interpreted as benign based on ultrasound findings and to clarify the pathological features of these malignant nodules.

\section{Materials and Methods}

We reviewed 53,533 thyroid nodules that were evaluated using US at Kuma Hospital between April 2012 and June 2015. US was performed using the APLIO 80 SSA-770A system (Toshiba Medical Systems Co., Ltd., Otawara, Japan) or the APLIO 500 TUS-A500 (Toshiba) system with the PLT-805AT probe (5- and 12-MHz, Toshiba) or the PLT-1005BT probe (5- and 14-MHz, Toshiba). US examination and reporting was routinely performed by 14 clinical technologists, 12 of whom were registered medical sonographers certified by The Japan Society of Ultrasonics in Medicine. The US reports were interpreted based on the US classification (USC) proposed by Ito et al. ( Table 1) [4], with USC scores used to identify malignant lesions (3.5-5.0), borderline lesions (3), and benign lesions (2.0-2.5). For the present study, benign US findings in our classification included lesions with low or very low suspicion patterns based on the American Thyroid Association guidelines [1].

A total of 37,151 nodules $(69.4 \%)$ were initially considered benign (USC 2.0-2.5), including 2,804 nodules (7.5\%) that were surgically resected. Among the resected nodules, 173 nodules ( $6.2 \%$ ) were histologically confirmed to be malignant, which corresponded to an incidence of $0.5 \%$ for malignancy among initially "benign" lesions. However, 11 of the 173 malignant thyroid nodules were excluded because internal echogenicity could not be observed. Therefore, we retrospectively re-evaluated the US findings for 162 malignant nodules that were originally interpreted as benign. The review was performed by one registered medical sonographer (T.F.).

When multiple thyroid nodules were present, they were evaluated separately. The potential US findings included taller-than-wide shape, margin status, echogenicity, punctate microcalcification, rim calcification with a small extrusive soft tissue component, and extrathyroidal extension. Taller-than-wide shape was defined as a ratio of $\geq 1$ between the anteroposterior diameter and the transverse diameter. The patients' clinical data, US findings, and US images were obtained from their medical records. Pathological findings were reviewed using representative microscopic preparations. The statistical analyses were performed using Fisher's probability test, and differences were considered significant at $p$-values of $<0.05$.

\section{Results}

- Table 2 shows the re-evaluated US findings for the 162 malignant thyroid nodules, which included solid nodules (121 cases, $74.7 \%$;

- Fig. 1a,b), focally cystic solid nodules (37 cases, $22.8 \%$ ), and mainly cystic nodules (4 cases, $2.5 \%$; $\triangleright$ Fig. 1c). Hypoechoic results were observed for 59 nodules (36.4\%; 51 solid nodules, 7 focally cystic solid nodules, and 1 mainly cystic nodule), and irregular margins were observed for 103 nodules (63.6\%; > Fig. 1d). These findings were also observed for $65.7 \%$ of microcarcinomas $(<1.0 \mathrm{~cm})$, and punctate microcalcifications were identified in 29 nodules $(17.9 \%$; -Fig. 1e), with a trend towards increasing frequency at larger sizes. A taller-than-wide shape was observed for 33 nodules (20.4\%; > Fig. 1f), and the incidence was significantly higher in $<2.0 \mathrm{~cm}$ nodules than in $>2.0 \mathrm{~cm}$ nodules $(p=0.0014)$. We did not detect any cases with disrupted rim calcification, small extrusive hypoechoic soft tissue components, or extrathyroidal extension.

The histological diagnoses included PTC (146 nodules, 90.1\%), FTC (12 nodules, $7.4 \%$ ), poorly differentiated thyroid carcinoma ( 1 nodule, $0.6 \%$ ), medullary thyroid carcinoma ( 2 nodules, $1.2 \%$ ), and well differentiated carcinoma-not otherwise specified ( 1 nodule, $0.6 \%$ ). Among the 146 PTC nodules, 40 nodules ( $27.4 \%$ ) were variants, including the encapsulated variant ( $\mathbf{F i g}$. 2 ), follicular vari-

- Table 1 Ultrasonographic classification (USC) for thyroid nodules in Kuma Hospital and ATA guidelines.

\begin{tabular}{|l|l|l|l|}
\hline \multicolumn{2}{|l|}{ Kuma Hospital } & & ATA guidelines \\
\hline USC & Description & Interpretation & Sonographic pattern \\
\hline 1 & Round or oval anechoic lesion & Benign & Benign \\
\hline 2 & $\begin{array}{l}\text { Regular-shaped nodule with cystic change. The echo level of the solid lesion is } \\
\text { similar to that of normal thyroid }\end{array}$ & Benign & Very low suspicion \\
\hline 2.5 & $\begin{array}{l}\text { Nodule with cystic change, partially irregular shape and/or strong echoes } \\
\text { internally or at the capsule }\end{array}$ & Benign & Low suspicion \\
\hline 3 & $\begin{array}{l}\text { Solid and regular-shaped nodule. Internal echo is homogeneous or may have } \\
\text { strong echoes internally or at the capsule }\end{array}$ & Borderline & Intermediate suspicion \\
\hline 3.5 & \begin{tabular}{l} 
Solid nodule with focally irregular shape \\
\hline 4
\end{tabular} & $\begin{array}{l}\text { Solid and irregular-shaped nodule. Internal echo is usually low and may have } \\
\text { fine strong echoes internally }\end{array}$ & Malignant \\
\hline 4.5 & Solid and irregular-shaped nodule with minor extrathyroidal extension & High suspicion \\
\hline 5 & Solid and irregular-shaped nodule with extrathyroidal extension & High suspicion \\
\hline$*$ Markedly calcified nodules are not evaluated. & Malignant & High suspicion \\
\hline
\end{tabular}


- Table 2 Re-evaluated ultrasound findings for 162 malignant thyroid nodules that were interpreted as benign based on ultrasound findings.

\begin{tabular}{|c|c|c|c|c|c|c|}
\hline & Total $N=162$ & $\begin{array}{l}\text { Low echogenicity } \\
\mathrm{N}=59(36.4 \%)\end{array}$ & $\begin{array}{l}\text { Irregular margins } \\
\mathrm{N}=103(63.6 \%)\end{array}$ & $\begin{array}{l}\text { Punctate } \\
\text { microcalcification } \\
\mathrm{N}=\mathbf{2 9}(\mathbf{1 7 . 9 \% )}\end{array}$ & $\begin{array}{l}T / W \geq 1 \\
N=33(20.4 \%)\end{array}$ & $\begin{array}{l}\text { Invasiveness }{ }^{\# \#} \\
\mathrm{~N}=\mathbf{0}\end{array}$ \\
\hline \multicolumn{7}{|l|}{ Size } \\
\hline$<10 \mathrm{~mm}$ & 35 & 18 (51.4\%) & 23 (65.7\%) & $4(11.4 \%)$ & 11 (31.4\%) & 0 \\
\hline $10-20 \mathrm{~mm}$ & 75 & 29 (38.7\%) & 51 (68.0\%) & 14 (18.7\%) & 19 (25.3\%) & 0 \\
\hline $20-40 \mathrm{~mm}$ & 32 & $6(18.8 \%)$ & 19 (59.4\%) & $6(18.8 \%)$ & $2(6.3 \%)$ & 0 \\
\hline$\geq 40 \mathrm{~mm}$ & 20 & $6(30.0 \%)$ & $10(50.0 \%)$ & $5(25.0 \%)$ & $1(5.0 \%)$ & 0 \\
\hline \multicolumn{7}{|l|}{ Histology } \\
\hline PTC & 146 (90.1\%) & $51(34.9 \%)$ & 94 (64.4\%) & 27 (18.5\%) & $31(21.2 \%)$ & 0 \\
\hline Classic & $106(72.6 \%)$ & 46 & 82 & 20 & 24 & 0 \\
\hline Encapsulated $\mathrm{V}^{\#}$ & 25 (17.1\%) & 2 & 14 & 7 & 4 & 0 \\
\hline Follicular V\# & $11(7.5 \%)$ & 1 & 6 & 1 & 1 & 0 \\
\hline Macrofollicular $\mathrm{V}^{\#}$ & $7(4.8 \%)$ & 0 & 5 & 0 & 1 & 0 \\
\hline Cribriform V & $3(2.1 \%)$ & 2 & 0 & 0 & 1 & 0 \\
\hline Tall cell V & $1(0.7 \%)$ & 0 & 0 & 0 & 1 & 0 \\
\hline Oxyphilic cell V & 1 (0.7\%) & 0 & 0 & 0 & 0 & 0 \\
\hline FTC & $12(7.4 \%)$ & $6(50.0 \%)$ & $7(58.3 \%)$ & $1(8.3 \%)$ & $2(16.7 \%)$ & 0 \\
\hline Minimally invasive & $7(58.3 \%)$ & 4 & 3 & 1 & 1 & 0 \\
\hline Widely invasive & $5(41.7 \%)$ & 2 & 4 & 0 & 1 & 0 \\
\hline PDTC & $1(0.6 \%)$ & 0 & $1(100 \%)$ & 0 & 0 & 0 \\
\hline MTC & $2(1.2 \%)$ & $2(100 \%)$ & $1(50.0 \%)$ & $1(50.0 \%)$ & 0 & 0 \\
\hline WDC-NOS & $1(0.6 \%)$ & 0 & 0 & 0 & 0 & 0 \\
\hline
\end{tabular}

\#: overlapping, V: variant, \#\#: rim calcifications with a small extrusive soft tissue component and extrathyroidal extension; T/W: taller-than-wide shape, PTC: papillary thyroid carcinoma, FTC: follicular thyroid carcinoma, PDTC: poorly differentiated thyroid carcinoma, MTC: medullary thyroid carcinoma, WDC-NOS: well differentiated carcinoma-not otherwise specified.
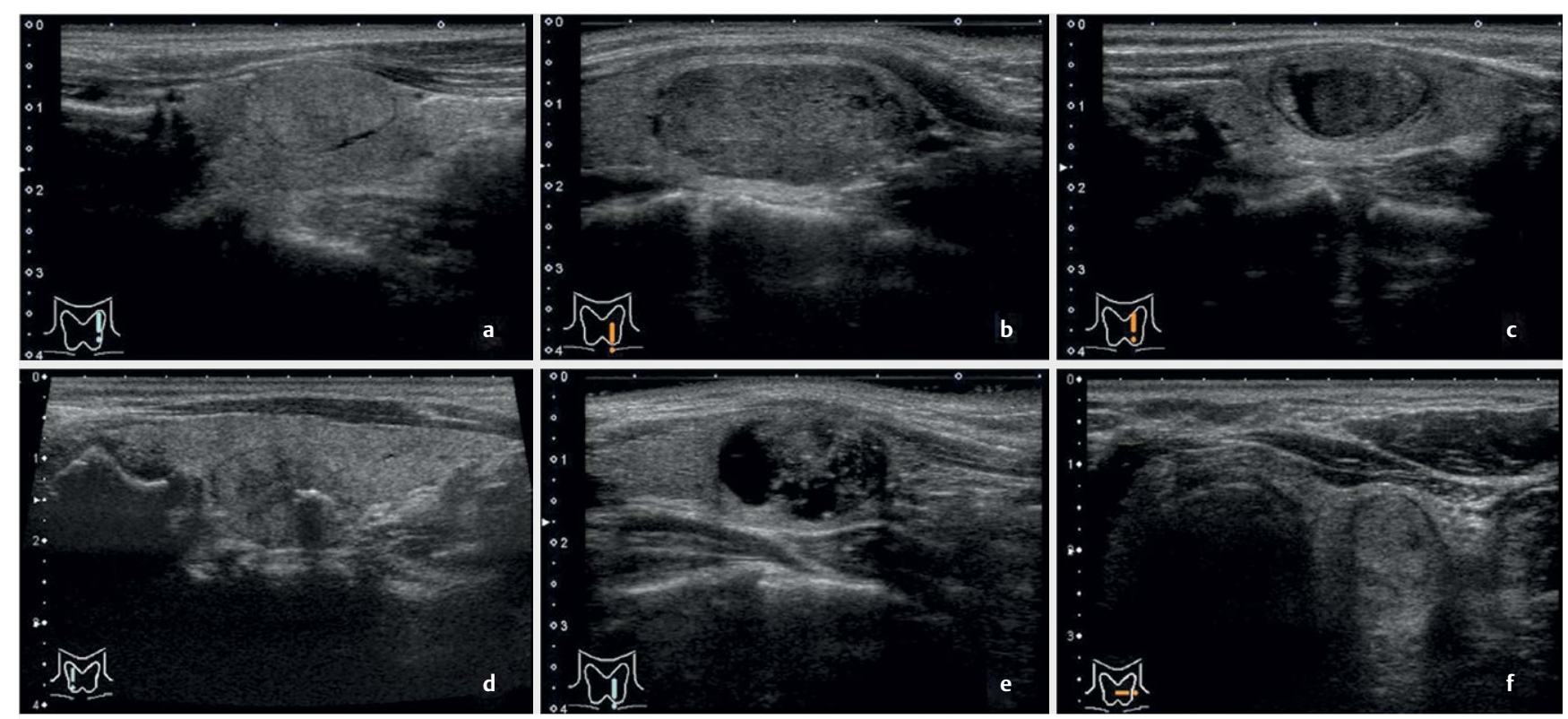

-Fig. 1 Ultrasound findings for malignant thyroid nodules that were originally interpreted as benign based on ultrasound findings.

a Solid isoechoic nodule. b Solid hypoechoic nodule. c Cystic nodule. $\mathbf{d}$ Irregular margin. e Punctate microcalcifications. $\mathbf{f}$ Taller-than-wide shape ( a-e : B-mode, longitudinal view, $\mathbf{f}: \mathrm{B}$-mode, transverse view). 


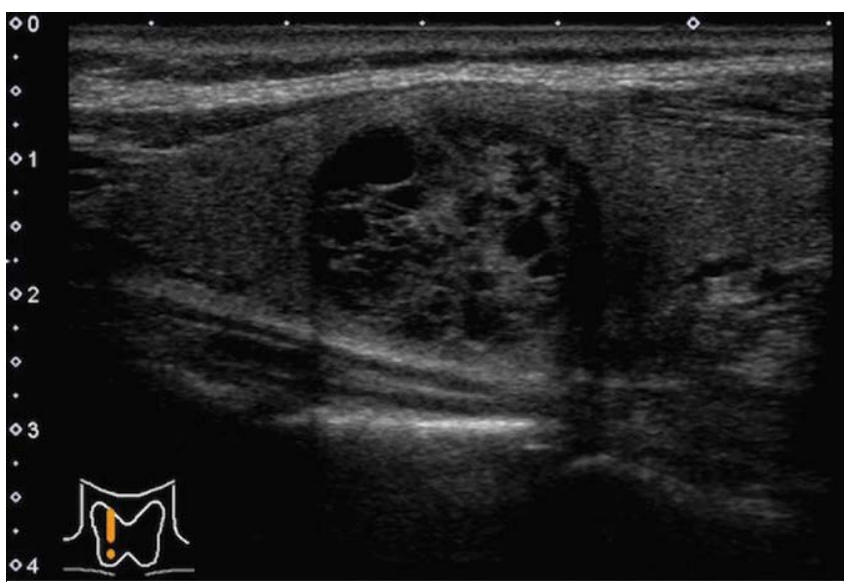

Fig. 2 Papillary carcinoma, encapsulated variant. The mixed solid and cystic nodule was round and well-defined, with no punctate microcalcification (B-mode, longitudinal view).

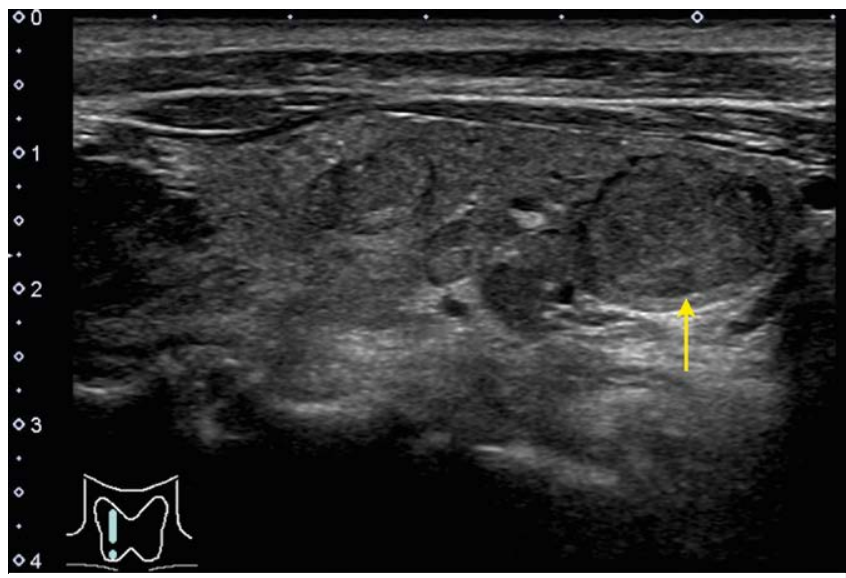

Fig. 3 Papillary carcinoma, encapsulated and follicular variant. The isoechoic solid nodule (arrow) is surrounded by a low echoic rim (B-mode, longitudinal view).

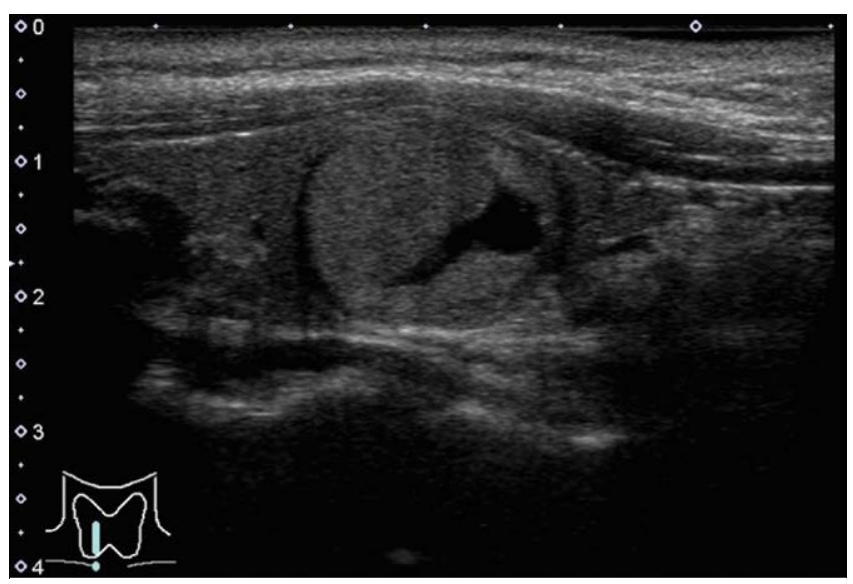

Fig. 4 Papillary carcinoma, encapsulated and macrofollicular variant. The isoechoic solid nodule contains a focal cystic lesion without invasiveness or punctate microcalcification (B-mode, longitudinal view). ant (FV; $>$ Fig. 3), macrofollicular variant ( $\triangleright$ Fig. 4), and the cribriform, tall cell, and oxyphilic cell variants. In two medullary thyroid carcinoma cases, the calcitonin levels of both the serum and needle wash-out fluids during aspiration were increased.

- Table 3 shows that 134 nodules $(82.7 \%$ ) were re-categorized into patterns with higher ROMs (high suspicion: 119 nodules [73.5\%], intermediate suspicion: 15 nodules [9.3\%]). The nodules' size did not affect this re-categorization. Low suspicion and very low suspicion patterns were observed for 16 nodules $(9.9 \%)$ and 12 nodules ( $7.4 \%)$, respectively, with higher incidences observed for larger nodules than for smaller nodules.

Aspiration cytology revealed that 128 nodules (79.0\%) had suspected or confirmed malignancy. Among the 14 nodules that were reported to be benign, 8 nodules (57.1\%) were re-classified into the high suspicious pattern. Among the 28 nodules that still had low or very low suspicion patterns, 17 nodules (60.7\%) were diagnosed with suspected or confirmed malignancy based on aspiration cytology.

Among the 25 PTC nodules that were still considered benign after the re-evaluation, 10 nodules $(40.0 \%)$ were variants, including the encapsulated, follicular, macrofollicular, and oxyphilic cell variants. Two FTC cases with low or very low suspicion patterns after the re-evaluation were minimally and widely invasive FTC, respectively. In the latter case, the satellite nodules were originally interpreted as a benign nodular goiter ( $\triangleright$ Fig. 5).

\section{Discussion}

US is the most important imaging modality for evaluating thyroid nodules, and the American Thyroid Association guidelines [1] classify the US findings into five patterns: high suspicion, intermediate suspicion, low suspicion, very low suspicion, and benign. Each category has an estimated ROM and the indication for FNAC is determined based on the pattern and tumor size. Thus, the US-based categorization of thyroid nodules plays an important role in a patient's clinical management.

This retrospective study evaluated US findings for 162 thyroid nodules that had been interpreted as benign based on US findings but were subsequently confirmed to be malignant based on histological examination. The reported ROMs for low and very low suspicion patterns are $5-10 \%$ and $<3 \%$, respectively $[1,7,8]$, although the present study revealed ROMs of $0.5 \%$ among all cases and $6.2 \%$ among cases that involved resection. Nevertheless, differences in the diagnostic criteria, US classification, and study selection criteria preclude a head-to-head comparison of the ROM values.

The present study revealed that $82.7 \%$ of thyroid nodules with initially low or very low suspicion patterns were subsequently re-categorized as having high or intermediate suspicion patterns based on the presence of more than one of the following: hypoechoic solid mass, irregular margins, punctate microcalcification, and a taller-than-wide shape [9-12]. Interestingly, irregular margins $(63.6 \%)$ and low echogenicity (36.4\%) were more common than punctate microcalcification (17.9\%) and taller-than-wide shape (20.4\%), and the former findings were even common for microcarcinomas (65.7\% and $51.4 \%$, respectively). However, we did not detect rim calcification with a small extrusive soft tissue component and extrathyroidal extension. The under-interpretation 
- Table 3 Re-evaluated ultrasound patterns for 162 malignant thyroid nodules that were interpreted as benign based on ultrasound findings.

\begin{tabular}{|c|c|c|c|c|c|}
\hline & Total $\mathrm{N}=162$ & $\begin{array}{l}\text { High } \\
\mathrm{N}=119 \text { (73.5\%) }\end{array}$ & $\begin{array}{l}\text { Intermediate } \\
\mathrm{N}=15(9.3 \%)\end{array}$ & $\begin{array}{l}\text { Low } \\
N=16 \text { (9.9\%) }\end{array}$ & $\begin{array}{l}\text { Very low } \\
N=12(7.4 \%)\end{array}$ \\
\hline \multicolumn{6}{|l|}{ Size } \\
\hline$<10 \mathrm{~mm}$ & 35 & $26(74.3 \%)$ & $6(17.1 \%)$ & $2(5.7 \%)$ & $1(2.9 \%)$ \\
\hline $10-20 \mathrm{~mm}$ & 75 & $60(80.0 \%)$ & $5(6.7 \%)$ & $8(10.7 \%)$ & $2(2.7 \%)$ \\
\hline $20-40 \mathrm{~mm}$ & 32 & $21(65.6 \%)$ & $2(6.3 \%)$ & $3(9.4 \%)$ & $6(18.8 \%)$ \\
\hline$\geq 40 \mathrm{~mm}$ & 20 & $12(60.0 \%)$ & $2(10.0 \%)$ & $3(15.0 \%)$ & $3(15.0 \%)$ \\
\hline \multicolumn{6}{|l|}{ Cytology } \\
\hline ND/UNS & 1 & 0 & 0 & $1(100 \%)$ & 0 \\
\hline Benign & 14 & $8(57.1 \%)$ & 0 & $4(28.6 \%)$ & $2(14.3 \%)$ \\
\hline AUS & 13 & $8(61.5 \%)$ & $2(15.4 \%)$ & $1(7.7 \%)$ & $2(15.4 \%)$ \\
\hline Follicular neoplasm & 6 & $4(66.7 \%)$ & $1(16.7 \%)$ & 0 & $1(16.7 \%)$ \\
\hline Suspected malignancy & 22 & $16(72.7 \%)$ & 0 & $4(18.2 \%)$ & 2 \\
\hline Malignant & 106 & $83(78.3 \%)$ & $12(11.3 \%)$ & $6(5.7 \%)$ & $5(4.7 \%)$ \\
\hline \multicolumn{6}{|l|}{ Histology } \\
\hline PTC & 146 (90.1\%) & $108(74.0 \%)$ & $13(8.9 \%)$ & $15(10.3 \%)$ & $10(6.9 \%)$ \\
\hline Classic & 106 & 82 & 9 & 8 & 7 \\
\hline Encapsulated $\mathrm{V}^{\#}$ & 25 & 18 & 1 & 3 & 3 \\
\hline Follicular $\mathrm{V}^{\#}$ & 11 & 7 & 1 & 3 & 0 \\
\hline Macrofollicular V\# & 7 & 5 & 0 & 1 & 1 \\
\hline Cribriform V & 3 & 1 & 2 & 0 & 0 \\
\hline Tall cell V & 1 & 1 & 0 & 0 & 0 \\
\hline Oxyphilic cell V & 1 & 0 & 0 & 1 & 0 \\
\hline FTC & $12(7.4 \%)$ & $8(66.7 \%)$ & $2(16.7 \%)$ & $1(8.3 \%)$ & $1(8.3 \%)$ \\
\hline Minimally invasive & 7 & 4 & 2 & 1 & 0 \\
\hline Widely invasive & 5 & 4 & 0 & 0 & 1 \\
\hline PDTC & $1(0.6 \%)$ & $1(100 \%)$ & 0 & 0 & 0 \\
\hline MTC & $2(1.2 \%)$ & $2(100 \%)$ & 0 & 0 & 0 \\
\hline WDC-NOS & $1(0.6 \%)$ & 0 & 0 & 0 & $1(100 \%)$ \\
\hline
\end{tabular}
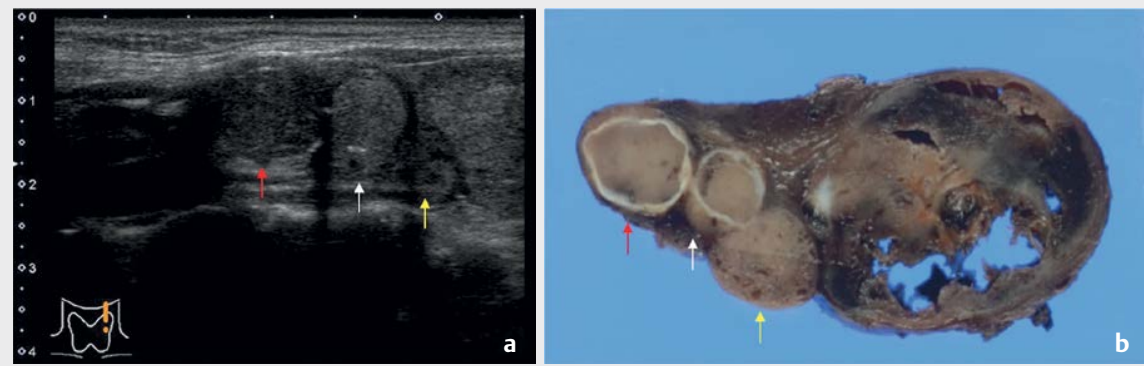

Fig. 5 Widely invasive follicular thyroid carcinoma. Satellite nodules (red, yellow, and white arrows) were interpreted as a benign nodular goiter (a B-mode, longitudinal view, b cut surface). 
might be related to inter-observer variability or different diagnostic criteria of US classification. In addition, we might have overlooked the findings suspecting malignancy or tended to avoid over-diagnosis in routine examination.

Inter-observer variability in the sonographic evaluation of thyroid nodules has been frequently discussed [13, 14], with low agreement values observed for subjective and qualitative findings, such as irregular margins and low echogenicity [13-15]. These features were frequently detected among malignant thyroid nodules that were originally interpreted as benign. In contrast, the present study less frequently detected more objective findings (e. g., punctate microcalcification and the taller-than-wide shape) and more easily recognizable findings (rim calcification with a small extrusive soft tissue component and extrathyroidal extension). Therefore, we conclude that more careful observation, especially in cases with irregular margins and low echogenicity, will further improve the diagnostic accuracy of thyroid US and decrease the incidences of thyroid nodules with low or very low suspicion patterns. It is also important to be aware that findings suggestive of malignancy can even be detected for microcarcinomas.

It has been reported that malignancy mainly involves FV-PTC and FTC for nodules with a low suspicion pattern [5, 6]. We have also reported that US findings of cribriform variant of PTC are similar to those of a follicular tumor or a nodular goiter [16]. The present study also revealed that $40 \%$ of PTC nodules still had benign ultrasound findings after their re-evaluation, which involved the encapsulated, follicular, macrofollicular, or oxyphilic cell variants. It is also important to be aware that the satellite nodules of widely invasive FTC may be confused with an adenomatous goiter.

US elastography is an emerging technique that reflects the stiffness of the lesion and could be helpful for identifying nodules with an increased risk for malignancy [17-20]. Recently, it has also been reported that semiquantitative elastosonography is a valuable tool in the characterization of thyroid nodules and seems to be more sensitive than contrast-enhanced ultrasound [21-24]. However, we have not performed this technique in routine examinations. Therefore, we are unable to include data concerning US elastography in this study. The new techniques are not popular in Japan. We expect that under-interpretation will decrease by using such techniques in the future.

\section{Conflict of Interest}

The authors declare no conflict of interest.

\section{References}

[1] Haugen BR, Alexander EK, Bible KC, Doherty GM, Mandel SJ, Nikiforov YE et al. 2015 American Thyroid Association Management Guidelines for Adult Patients with Thyroid Nodules and Differentiated Thyroid Cancer: The American Thyroid Association Guidelines Task Force on Thyroid Nodules and Differentiated Thyroid Cancer. Thyroid 2016; 26: 1-133

[2] Horvath E, Majlis S, Rossi R, Franco C, Niedmann JP, Castro A et al. An ultrasonogram reporting system for thyroid nodules stratifying cancer risk for clinical management. J Clin Endocrinol Metab 2009; 94: $1748-1751$
[3] Tae HJ, Lim DJ, Baek KH, Park WC, Lee YS, Choi JE et al. Diagnostic value of ultrasonography to distinguish between benign and malignant lesions in the management of thyroid nodules. Thyroid 2007; 17: 461-466

[4] Ito Y, Amino N, Yokozawa T, Ota H, Ohshita M, Murata N et al. Ultrasonographic evaluation of thyroid nodules in 900 patients: Comparison among ultrasonographic, cytological, and histological findings. Thyroid 2007; 17: 1269-1276

[5] Moon WJ, Jung SL, Lee JH, Na DG, Baek JH, Lee YH et al. Benign and malignant thyroid nodules: US differentiation-multicenter retrospective study. Radiology 2008; 247: 762-770

[6] Komatsu M, Hanamura N, Tsuchiya S, Seki T, Kuroda T. Preoperative diagnosis of the follicular variant of papillary carcinoma of the thyroid: Discrepancy between image and cytologic diagnoses. Radiat Med 1994; 12: 293-299

[7] Smith-Bindman R, Lebda P, Feldstein VA, Sellami D, Goldstein RB, Brasic $\mathrm{N}$ et al. Risk of Thyroid Cancer Based on Thyroid Ultrasound Imaging Characteristics: Results of a Population-Based Study. JAMA Intern Med 2013; 173: 1788-1796

[8] Yi KH. The Revised 2016 Korean Thyroid Association Guidelines for Thyroid Nodules and Cancers: Differences from the 2015 American Thyroid Association Guidelines. Endocrinol Metab 2016; 31: 373-378

[9] Kobayashi K, Fujimoto T, Ota H, Hirokawa M, Yabuta T, Masuoka H et al. Calcifications in Thyroid Tumors on Ultrasonography: Calcification Types and Relationship with Histopathological Type. Ultrasound International Open 2018 (in press)

[10] Moon W], Baek JH, Jung SL, Kim DW, Kim EK, Kim JY et al. Ultrasonography and the Ultrasound-Based Management of Thyroid Nodules: Consensus Statement and Recommendations. Korean J Radiol 2011; 12: $1-14$

[11] Wong KT, Ahuja AT. Ultrasound of thyroid cancer. Cancer Imaging 2005; 5: 157-166

[12] Hoang JK, Lee WK, Lee M, Johnson D, Farrell S. US Features of Thyroid Malignancy: Pearls and Pitfalls. Radiographics 2007; 27: 847-860

[13] Park CS, Kim SH, Jung SL, Kang BJ, Kim JY, Choi J] et al. Observer variability in the sonographic evaluation of thyroid nodules. J Clin Ultrasound 2010; 38: 287-293

[14] Choi SH, Kim EK, Kwak JY, Kim MJ, Son EJ. Interobserver and intraobserver variations in ultrasound assessment of thyroid nodules. Thyroid 2010; 20: 167-172

[15] Hambly NM, Gonen M, Gerst SR, Li D, Jia X, Mironov S et al. Implementation of evidence-based guidelines for thyroid nodule biopsy: A model for establishment of practice standards. AJR Am J Roentgenol 2011; 196: 655-660

[16] Fujimoto T, Hirokawa M, Ota H, Yabuta T, Fukushima M, Kobayashi K et al. Characteristic sonographic features of cribriform papillary thyroid carcinoma for differentiation from other thyroid nodules. J Med Ultrason 2015; 42: 83-87

[17] Kim HJ, Kwak MK, Choi IH, Jin SY, Park HK, Byun DW et al. Utility of shear wave elastography to detect papillary thyroid carcinoma in thyroid nodules: Efficacy of the standard deviation elasticity. Korean J Intern Med 2018, doi:10.3904/kjim.2016.326. [Epub ahead of print]

[18] Magri F, Chytiris S, Capelli V, Gaiti M, Zerbini F, Carrara R et al. Comparison of elastographic strain index and thyroid fine-needle aspiration cytology in 631 thyroid nodules. J Clin Endocrinol Metab 2013; 98: 4790-4797

[19] Veyrieres JB, Albarel F, Lombard JV, Berbis ], Sebag F, Oliver C et al. threshold value in Shear Wave elastography to rule out malignant thyroid nodules: a reality? Eur J Radiol 2012; 81: 3965-3972

[20] Samir AE, Dhyani M, Anvari A, Prescott ], Halpern EF, Faquin WC et al. Shear-wave elastography for the preoperative risk stratification of follicular-patterned lesions of the thyroid: diagnostic accuracy and optimal measurement plane. Radiology. 2015; 277: 565-573 
[21] Cantisani V, Consorti F, Guerrisi A, Guerrisi I, Ricci P, Di Segni M et al. Prospective comparative evaluation of quantitative-elastosonography (Q-elastography) and contrast-enhanced ultrasound for the evaluation of thyroid nodules: preliminary experience. Eur J Radiol 2013; 82: 1892-1898

[22] Cantisani V, Bertolotto M, Weskott HP, Romanini L, Grazhdani H, Passamonti $\mathrm{M}$ et al. Growing indications for CEUS: The kidney, testis, lymph nodes, thyroid, prostate, and small bowel. Eur J Radiol 2015; 84 : 1675-1684
[23] Sidhu PS, Cantisani V, Dietrich CF, Gilja OH, Saftoiu A, Bartels E et al. The EFSUMB Guidelines and Recommendations for the Clinical Practice of Contrast-Enhanced Ultrasound (CEUS) in Non-Hepatic Applications: Update 2017 (Long Version). Ultraschall Med. 2018; 39: e2-e44

[24] Dietrich CF, Averkiou M, Nielsen MB, Barr RG, Burns PN, Calliada F et al. How to perform Contrast-Enhanced Ultrasound (CEUS). Ultrasound Int Open 2018; 4: E2-E15 